\title{
Spectroscopic Diagnostic of Spark Discharge Plasma at Atmospheric Pressure
}

\author{
Laslov Geza ${ }^{1,2^{*}}$, Shuaibov Alexander ${ }^{1}$, Szegedi Sándor ${ }^{2}$ and László Elemér ${ }^{2}$ \\ 1. Uzhgorod National University, Uzhgorod 88000, Ukraine \\ 2. Department of Meteorology Debrecen, Institute of Earth Sciences, Faculty of Science and Technology, University of Debrecen, \\ Debrecen 4027, Hungary
}

Received: December 05, 2013 / Accepted: January 06, 2014 / Published: March 25, 2014.

\begin{abstract}
The emission of $\mathrm{CuInSe}_{2}$-based spark discharge plasma at atmospheric pressure in air has been investigated by optical emission spectroscopy method. The plasma was formed by action of the high voltage pulse generator (with nanosecond pulse) on the corresponding electrodes ( $\mathrm{CuInSe}_{2}$ compound). The emission characteristics have been obtained for the spark discharge plasma at $3 \mathrm{~mm}$ interelectrode distance. It was established that the spark discharge plasma radiation was determined by decay products of the compound from which electrodes were made. The most suitable spectral lines for plasma diagnostics is atomic copper lines in the visible spectrum and atomic indium lines in UV (ultraviolet) and visible spectrum.
\end{abstract}

Key words: Spark discharge, optical emission spectroscopy, emission characteristic, excited states, $\mathrm{CuInSe}_{2}$ compound.

\section{Introduction}

The CuInSe $e_{2}$ compound is one of the most promising materials for solar energy utilization with high efficiency [1-7]. Obtaining thin films based on this compound requires careful selection of the external conditions destruction. Ablation and spraying compounds by nanosecond spark discharge makes it possible to control the process of electrode erosion by regulating duration of the voltage and current pulse [8], and to determine the optimal conditions for thin films or optimization of nanoparticles synthesis conditions [9].

Currently known scientific research about the radiation characteristics of microsecond spark discharge plasma at atmospheric pressure studied in Ref. [10]. In this work, the spark discharge was ignited between copper electrodes at $1 \mathrm{~mm}$ spark gap. The amplitude of current pulse amounted $\sim 80 \mathrm{~A}$ and its duration was $100 \mu \mathrm{s}$. The emission spectrum of these spark discharge plasma contained excited states

\footnotetext{
*Corresponding author: Laslov Geza, Postgraduate Student, research fields: laser plasma and plasma physics. E-mail: lgeza@ukr.net.
}

of copper atoms in ultraviolet and visible spectrum.

The plasma spark discharge radiation between metal electrodes at $0.5 \mathrm{~mm}$ spark gap investigated in Ref. [11]. The amplitude of the incident voltage pulses was $\sim 10 \mathrm{kV}$, full pulse width at half maximum $\sim 1 \mathrm{~ns}$. The ionic lines of electrode material in ultraviolet spectrum observed in the spectra of such discharge.

The basic parameters that influence the size of nanoparticles and velocity spraying of electrode material is the electron temperature and electron density. Thus, to establish the conditions necessary to control the synthesis of nanoparticles above mentioned parameters.

The main purpose of this work was determination the composition of the spark discharge plasma by using emission spectroscopy method. Our second important aim was to select the suitable spectral lines for determination of the electron temperature in the plasma.

\section{Experiments}

The scheme of experimental set-up is represented 
on the Fig. 1. The experiments were carried out using a high voltage pulse generator. Formation of high-voltage pulses is as follows. A $6.6 \mathrm{nF}$ capacitance is charged to a voltage of $10 \mathrm{kV}$, then there is its discharge through a pulse thyratron and the primary winding of the step-up pulse transformer. Electrodes were connected to the secondary winding of the transformer through high voltage cable. The electrodes represented a $\mathrm{CuInSe}_{2}$ compound. The step-up pulse transformer allows to obtain a voltage with $30-35 \mathrm{kV}$ amplitude on the electrodes. Voltage and current pulse duration was $10 \mathrm{~ns}$, pulse repetition frequency varied within $10-100 \mathrm{~Hz}$. The next important element of experimental set-up is discharge chamber (stainless steel) with two quartz window. The system of electrodes was placed on a dielectric (vinyl plastic) flange. The residual air pressure in the discharge chamber was 1 atm. The radiation was analyzed with the help of an MDR-2 monochromator with a grating of $1200 \mathrm{~L} / \mathrm{mm}$ in the spectral region 250-600 nm.

Time-averaged emission spectra of radiation was registered with the help of an photomultiplier tube FEU-106, direct current amplifer and recorder KSP-4. The registration system FEU-106 and MDR-2 were calibrated with respect to the radiation of hydrogen and tungsten lamps. This allowed us to measure the relative intensities of the radiation lines $\left(I / k_{\lambda}\right.$, where $k_{\lambda}$ is the relative spectral sensitivity of the registration

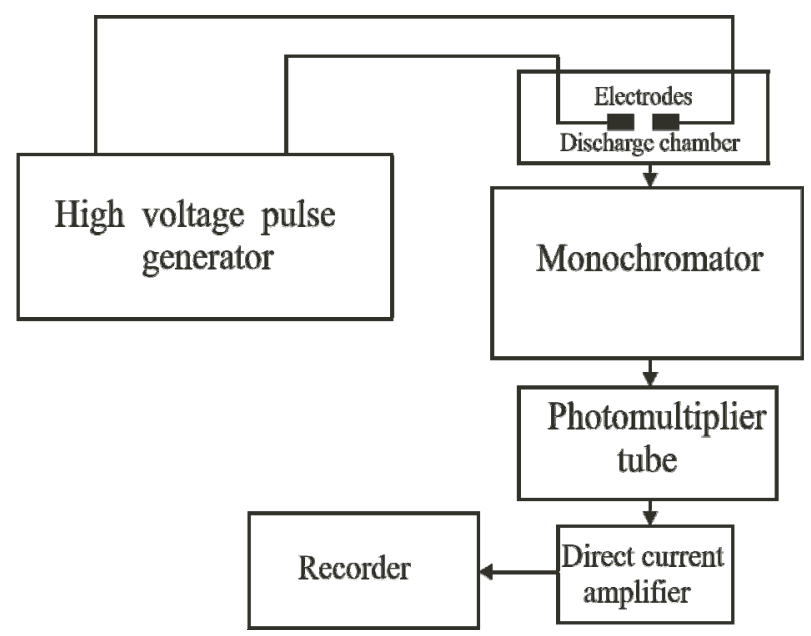

Fig. 1 The scheme of experimental set-up. system. The identification of spectral lines was performed using handbooks [12-14].

\section{Results and Discussion}

Time-averaged emission spectra of spark discharge plasma with electrodes based on copper indium diselenide compound is represented on the Fig. 2.

The spectrum included the folowing spectral lines of excited copper and indium atoms: 324.7; 327.4; $400.3 ; 407.3 ; 464.3 ; 510.6 ; 521.8 ; 570.0 ; 573.2 \mathrm{~nm} \mathrm{Cu}$ I i $283.7 ; 293.3 ; 303.9 ; 325.6 ; 410.2 ; 451.1 \mathrm{~nm}$ In I.

The spectral lines of excited states copper and indium shown in the Tables 1 and 2, respctively. It includes radiation wavelengths $(\lambda)$, intensities $(I)$, transition probabilities $(A)$, energies of upper 1 evels $\left(E_{u p}\right)$ and electron configurations of upper level.

The spectral lines of selenium excited atoms were not observed. In addition to the spectral lines of the electrode material recorded intense ionic line of nitrogen $500.5 \mathrm{~nm} \mathrm{~N}$ II. This line was observed in nanosecond discharges in air at atmospheric pressure during the first 50-150 ns, and then disappears as a result of the passage of effective recombination processes between ions and electrons of nanosecond discharge. As a result of these processes in the emission spectrum of the plasma in the later stages of the discharge appear some intense spectral lines of atomic nitrogen in the visible spectrum.

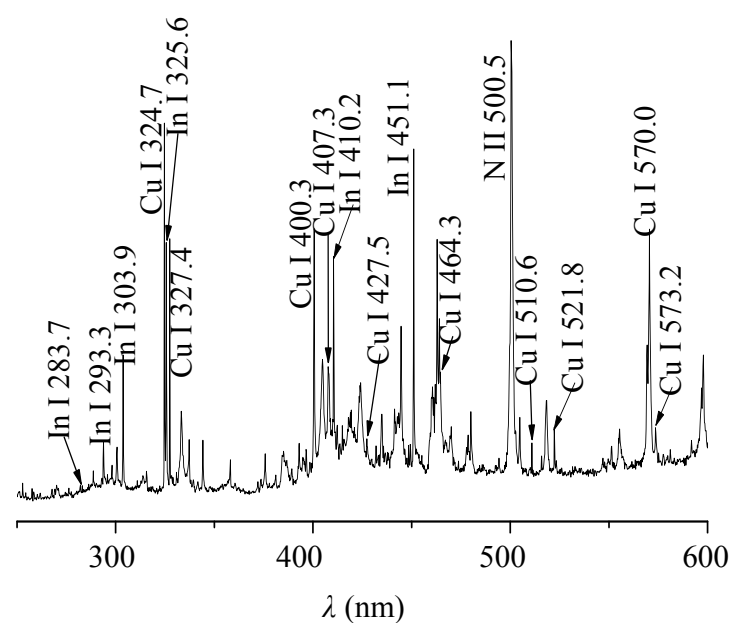

Fig. 2 Emission spectrum of spark discharge plasma. 
Table 1 Spectral lines of $\mathrm{CuI}$ excited atoms.

\begin{tabular}{|c|c|c|c|c|}
\hline$\lambda(\mathrm{nm})$ & $I$ (a.u.) & $A\left(10^{8} \mathrm{~s}^{-1}\right)$ & $E_{u p}(\mathrm{eV})$ & Term $_{\text {up }}$ \\
\hline 324.7 & 1.82 & 1.37 & 3.82 & $4 p^{2} \mathrm{P}_{1.5}$ \\
\hline 327.4 & 1.29 & 1.36 & 3.79 & $4 p^{2} \mathrm{P}_{0.5}$ \\
\hline 400.3 & 1.34 & - & 8.79 & $\mathrm{~s} 4 \mathrm{~d}^{\prime}{ }^{2} \mathrm{P}_{1.5}$ \\
\hline 407.3 & 0.7 & - & 8.02 & $\mathrm{~s} 5 \mathrm{~s}^{\prime 2} \mathrm{D}_{1.5}$ \\
\hline 427.5 & 0.38 & 0.345 & 7.74 & $\mathrm{~s} 5 \mathrm{~s}^{\prime}{ }^{4} \mathrm{D}_{3.5}$ \\
\hline 464.3 & 0.68 & - & 8.09 & $\mathrm{~s} 5 \mathrm{~s}^{\prime 2} \mathrm{D}_{1.5}$ \\
\hline 510.6 & 0.36 & 0.019 & 3.82 & $4 \mathrm{p}^{2} \mathrm{P}_{1.5}$ \\
\hline 515.3 & 0,3 & 0,6 & 6.19 & $4 \mathrm{~d}^{2} \mathrm{D}_{1.5}$ \\
\hline 521.8 & 0,4 & 0,75 & 6.19 & $4 \mathrm{~d}^{2} \mathrm{D}_{2.5}$ \\
\hline 570.0 & 1.34 & 0.024 & 3.82 & $4 p^{2} \mathrm{P}_{1.5}$ \\
\hline 573.2 & 0.43 & - & 7.73 & $5 \mathrm{~s}^{\prime}{ }^{4} \mathrm{D}_{3.5}$ \\
\hline
\end{tabular}

Table 2 Spectral lines of In I excited atoms.

\begin{tabular}{lllll}
\hline$\lambda(\mathrm{nm})$ & $I$ (a.u.) & $A\left(10^{8} \mathrm{~s}^{-1}\right)$ & $E_{u p}(\mathrm{eV})$ & Term ${ }_{\text {up }}$ \\
\hline 283.7 & 0.16 & - & 4.64 & $\mathrm{~s}^{2} \mathrm{p}^{2} \mathrm{P}_{2.5}$ \\
293.3 & 0.37 & 0.23 & 4.5 & $5 \mathrm{~s}^{2} 7 \mathrm{~s}^{2} \mathrm{~S}_{0.5}$ \\
303.9 & 0.76 & 1.11 & 4.07 & $5 \mathrm{~s}^{2} \mathrm{D}_{1.5}$ \\
325.6 & 1.28 & 1.3 & 4.08 & $5 \mathrm{~s}^{2} \mathrm{D}_{2.5}$ \\
410.2 & 1.21 & 0.5 & 3.02 & $5 \mathrm{~s}^{2} 6 \mathrm{~s}^{2} \mathrm{~S}_{0.5}$ \\
451.1 & 1.7 & 0.89 & 3.02 & $5 \mathrm{~s}^{2} 6 \mathrm{~s}^{2} \mathrm{~S}_{0.5}$ \\
\hline
\end{tabular}

The weak emission band of second positive system of nitrogen and j-system of $\mathrm{NO}$ were registered in the spectrum as well.

An intense spectral lines of copper ions in the spectrum of radiation, which could reliably identify not observed. Probably singly charged ions of copper formed in the ground state and react dielectronic recombination with electrons. As a result of the formation of excited copper atoms that decay with the emission spectral lines in the visible and ultraviolet wavelengths.

The most intensive spectral lines are ionic line of nitrogen $500.5 \mathrm{~nm} \mathrm{~N}$ II, excited atoms of copper 324.7; 327.4 CuI and indium 303.9, 410.2, $451.1 \mathrm{~nm}$ In I.

\section{Conclusions}

Thus, the emission spectrum of spark discharge plasma consisted of atomics lines of corresponding electrodes, atomic and ionic line of nitrogen. The most suitable spectral lines for plasma diagnostics is atomic copper lines in the visible spectrum and atomic indium lines in UV and visible spectrum.
These results can be used for a deeper understanding of the processes in spark discharge and to select the optimal conditions for the synthesis of nanoparticles of different sizes based on copper indium diselenide compound by pulsed nanosecond discharge.

\section{Acknowledgments}

This research was realized in the frames of TÁMOP 4.2.4. A/2-11-1-2012-0001 "National Excellence Program-Elaborating and operating in inland student and researcher personal support system". The project was subsidized by the European Union and cofinanced by the European Social Fund.

\section{References}

[1] Abdullah, H.; Habibi, S. J. Effects of Annealing Temperature on $\mathrm{CuInSe}_{2} / \mathrm{ZnS}$ Thin-Films Solar Cells Fabricated by Using Electron Beam Evaportation. Int. Journal of Photoenergy 2013, 2013, 1-5.

[2] Tsuoshi, M. Takahiro Wada First Principles Studies on Cd Doping in $\mathrm{CuInSe}_{2}$ and Related Compound during Chemical Bath Deposition of CdS Buffer Layer. Jpn. J. Appl. Phys. 2013, 52, 061201. 
[3] Matthew, G.; Panthani, C.; Jackson, S.; Dariya, K. R.; Dong, J. R.; Taylor, B. H.; et al. CuInSe ${ }_{2}$ Quantum Dot Solar Cells with High Open-Circuit Voltage. J. Phys. Chem. 2013, 4, 2030-2034.

[4] Ahmed, E.; Hill, A. E.; Pilkington, R. D.; Tomlinson, R. D.; Leppauori, J.; Levoska, J.; et al. Deposition and Characterization of Copper Indium Gallium Diselenide Thin Films by Laser Ablation and Flash Evaportation for Use in Solar Cells. Journals of Materials Science 1997, 32(24), 5611-5613.

[5] Zaretskaya, E. P.; Gremenok, V. F. Correlation between Raman Spectra and Structural Properties of $\mathrm{Zn}_{2-2 x} \mathrm{Cu}_{x} \mathrm{In}_{x} \mathrm{Se}_{2}$ Films. Optics and Spectroscopy 2007, 102(1), 77-82.

[6] Bodnar, I. V.; Gremenok, V. F. Optical Properties of Films of the Ternary Compound $\mathrm{CuIn}_{3} \mathrm{Se}_{5}$. Journal of Applied Spectroscopy 2007, 74(1), 90-94.

[7] Victor, P.; Nagaraju, J.; Krupahindi, S. P. Pulsed Excimer Laser Ablated Copper Indium Diselenide Thin Film. Solid State Communications 2000, 116(12), 649-653.

[8] Tabrizi, N. S.; Xu, Q.; Van Der Pers, N. M. A. Shmidt-Ott Generation of Mixed Metallic Nanoparticles from Immiscible Metals by Spark Discharge. J. Nanopart. Res. 2010, 12, 247-259.

[9] Hyuncheol, O.; Junho, J.; Jaehee, J.; Sangsoo, K. Synthesis of Titania Nanoparticles via Spark Discharge Method Using Air as a Carrier. Materials Science Forum 2007, 544-545, 143-146.

[10] Burakov, V. S.; Nevar, E. A.; Nedel'ko, M. I.; Savastenko, N. A.; Tarasenko, N. V. Spectroscopic Diagnostics for an Electrical Discharge Plasma in Liquid. Journal of Applied Spectroscopy 2009, 76(6), 856-863.

[11] Baksht, E. Kh.; Tarasenko, V. F.; Shut'ko, Yu. V.; Erofeev, M. V. Point-like Pulse Periodic UV Radiation Source with Short Pulse Duration. Quantum Electronics 2012, 42, 153-156.

[12] Smith, P. L.; Heise, C.; Esmond, J. R.; Kurucz, R. L. Atomic Spectral Line Database from CD-ROM 23 of R.L. Kurucz (Smithosian Astrophysical Observatory, Cambridge, 1995). http://cfa-www.harvard.edu/amp.

[13] Sansonetti, J. E.; Martin, W. C. Handbook of Basic Atomic Spectroscopic Data. J. Phys. Chem. Ref. Data 2005, 34, 1559.

[14] NIST 2011 National Institute of Standard and Technologies. http://www.nist.gov. 